results and future prospects in the field of transplantation. In addition to the problem of immunological rejection there are other difficulties, notably those in obtaining satisfactory numbers of donors, particularly from cadaver sources. Better methods of storing organs are also needed. Professor Woodruff ends with the hope that transplantation of organs from animals to man may eventually become successful.

The College of Pathologists is to be congratulated on this symposium-the first it has held. The report of it provides an up-to-date account of tissue and organ transplantation which should be of help to all who are interested in this field, and particularly pathologists.

\section{A Disease of Skin and Bowel}

In the last 25 years occasional reports have appeared describing what is apparently a new disease affecting chiefly the skin and the intestines. The condition was first recognized in 1942 by $R$. Degos and his colleagues, ${ }^{12}$ who initially called it "atrophic papulosquamous dermatitis," and later ${ }^{3}$ "malignant atrophic papulosis." An earlier report by W. Köhlmeier ${ }^{4}$ which referred to a case of skin necrosis in a patient thought to have thromboangiitis obliterans clearly describes the same condition, and hence the name KöhlmeierDegos disease has also been used.

The condition is rare. In a recent review W. E. Strole and others ${ }^{5}$ found only 19 reported cases. The majority of these were from European countries, a few from the U.S.A., and one $^{6}$ from Great Britain. Seventeen of the patients were males, and of these 14 were aged under 40 years. The initial presentation is a papular skin lesion on the trunk and limbs. The papules are at first pink or grey, several millimetres in diameter, and appear in crops. They remain unchanged for some tinnc, but later rapidly develop central umbilication and may coalesce to form larger lesions. With time they become less prominent and assume a rather mummified appearance, but they never disappear completely. At this stage the patient feels well, and, apart from the rash and transient burning or pruritus, has no symptoms. After a variable period, which may be weeks or years, abdominal pain, weakness, fatigue, loss of weight, and sometimes diari hoea develop. Intestinal perforation then follows and in most cases it is fatal, because multiple perforations occur either sinultaneously or at intervals. At laparotomy or necropsy the bowel wall is seen to be studded with multiple depressed white patches similar to the skin lesions. In three cases death was due to multiple cerebral infarcts.

Histologically the characteristic lesion is a change in the arterioles and small arteries. The affected vessels are occluded by relatively acellular fibrous thrombi, and the wall of the artery at the site of occlusion shows a subendothelial fibroplasia. The elastic lamina remains intact and at this level there is no inflammatory response either in the vessel wall or in the periarterial tissues. Elsewhere in the artery, however, an arteritis resembling that seen in polyarteritis nodosa may be found. Though clinically the disease presents mainly with skin and intestinal lesions, the arterial changes are in

\footnotetext{
Degos, R., Delort, J., and Tricot, R., Bull. Soc. franç. Derm. Syph., $1942,49,148$.

Lortat-Jacob, E., Garnier, G., and Benoit, C., ibid., 1942, 4), 281.

Kö Brit. F. Derm., 1954, 66, 304.

5 Strole, W. E., Clark, W. H., and Isselbacher, K. J., New Engl. 7. Med.,

6 Hall-Smith, S. P., Proc. roy. Soc. Med., 1964, 57, 519.
}

fact widespread and may be in any organ. The skin lesion is a non-specific combination of epidermal atrophy and dermal sclerosis, and the histological diagnosis rests on finding the characteristic vascular lesion in the small arteries of the reticular dermis.

Laboratory investigations do not reveal any specific changes. The course of the disease appears to be uniformly fatal, and so far all the therapeutic regimens which have been tried have failed.

Is this a new disease? From the published descriptions of the illness the clinical picture is apparently striking and it is unlikely that it would not have been recognized and reported by the astute clinicians of the early years of this century. The condition which it most closely resembles is polyarteritis nodosa. The clinical picture with the emphasis on the skin and the intestines is certainly unlike classical polyarteritis nodosa. Though the main lesion in the small arteries is apparently different from that of polyarteritis, yet some of the published photomicrographs do show a distinct arteritis in parts of the affected vessels. The time course of the illness and the lack of response to adrenal corticosteroids also suggest that though "malignant atrophic papulosis" is primarily a disease of small arteries and arterioles it may be distinct from polyarteritis nodosa. But it seems equally possible that, like Wegener's granulomatosis, it is a variant of a disease with protean manifestations.

\section{A Case for Cannabis?}

The full-page advertisement in The Times ${ }^{1}$ signed by prominent scientists, doctors, and intellectuals, urging that "the law against marihuana is immoral in principle and unworkable in practice," is only one of many recent appeals ${ }^{2}$ in Britain and the U.S.A. for a more permissive attitude.

Marihuana, "pot," and hashish are all forms of cannabis, and are obtained from the flowers or leaves of the female Indian hemp plant, Cannabis sativa. International legal control of cannabis came into being in 1925, when the League of Nations organized its second opium conference. ${ }^{3}$ The Egyptian delegate stated that 30 to $60 \%$ of the patients suffering from insanity in Egypt were cases of chronic hashishism. The conference agreed that the use of Indian hemp and its products should be authorized for medical and scientific purposes only, and that international trade should be strictly controlled. In Britain the Dangerous Drugs Act of 1920 was amended to include cannabis, and it is still included in the 1965 Act.

Cannabis has no known therapeutic value, ${ }^{4}$ and possibly as a result of this there has been little research into its pharmacology in man. Inhaled smoke produces initial effects within a few minutes and maximum response is obtained in half to one hour, persisting for some three to five hours. If the drug is taken in a conducive setting its effects commonly include tranquillity, apathy, and euphoria. Much less frequently fear, aggression, and hilarity are noted, these sometimes being seen when cannabis is used by an extrovert in a stimulating situation. With increasing doses changes in mood are followed by changes in perception including changes in

1 The Times, 24 July 1967.

2 Newsweek, 24 July 1967.

Report of the International Conference on Opium and Dangerous Drugs, Cmnd. 2461, 1925. H.M.S.O.

- Brit. med. F., 1964, 2, 1348.

s Eddy, N. B., Halbach, H., Ishbell, H., and Seevers, M. H., Bull. Wld Hlth Org., 1965, 38, 721 .

- Ciba Foundation Study Group 21, Hashish; its Chemistry and Pharmacology, 1965. London. 
perception of the passage of time and then by hallucinations There is also an idiosyncratic reaction resembling a psychosis; this is not dose-dependent, and the probability of its occurrence is apparently not related to the stability of the personality. Rarely hallucinations and fragmentation of thought processes occur and present as psychotic disturbances. The physical signs may include variations in blood pressure and pulse rate, bronchoconstriction, hypoglycaemia, and alimentary disturbances, though these features are not constant. More significant is the marked dilatation of conjunctival blood vessels which frequently occurs after first taking the drug.

The World Health Organization has defined a state of drug dependence of the cannabis type. ${ }^{5}$ There is a moderate to strong psychological dependence as a result of a desire for the subjective effects, but an absence of physical dependence-so no abstinence syndrome occurs-and there is no evidence of tolerance. Commenting on this, N. B. Eddy and his colleagues stated that individuals dependent on cannabis might suffer from " inertia, lethargy, self neglect, feelings of increased capability with consequent failure, and precipitation of psychotic episodes."

Research into the effects of cannabis in man is in progress in the U.S.A. and elsewhere. ${ }^{6}$ No objective assessment of the effects of prolonged administration of the drug has yet been published. There is still disagreement whether or not cannabis users are likely to progress to heroin and other " hard" drugs. An answer to both these questions is urgent. But while the effects of prolonged exposure to cannabis remain speculative it is irresponsible to encourage a more permissive attitude to the drug.

\section{Respiratory Burns}

On 28 November 1942 a disastrous fire occurred at the Cocoanut Grove night club in Boston in which 491 people lost their lives. Of the 114 casualties taken to the Massachusetts General Hospital, 75 were either dead on arrival or died of anoxia within minutes. Of the 39 who survived long enough to be treated, only three were entirely without respiratory symptoms. The clinical picture, ${ }^{1} x$-ray appearances, ${ }^{2}$ and pathology ${ }^{3}$ of these pulmonary injuries were well recorded. Only a small proportion of the victims had extensive burns, and most of the deaths were attributed to anoxaemia and poisoning by carbon monoxide and traces of oxides of nitrogen.

In 1945 A. R. Moritz ${ }^{4}$ and his co-workers published experimental work on dogs in which they showed that when hot air was blown into the larynx at $270^{\circ} \mathrm{C}$. the temperature of the air fell to $50^{\circ} \mathrm{C}$. in the trachea. Hot air and flame could burn the larynx and trachea but failed to produce pulmonary damage. On the other hand, inhaled steam produced severe pulmonary injury owing to its greater latent heat.

A review by $A$. W. Phillips and colleagues of cases treated at the Massachusetts General Hospital during $1939-57^{5-7}$ showed that in $42 \%$ of fatal cases the patient died of damage to the respiratory tract, about half of these in the first three days. They stressed the significance of deep flame burns around the nose and mouth, burning in an enclosed environment, and the inhalation of smoke and the products of incomplete combustion as ominous warning signs of pulmonary damage even in the absence of respiratory signs and symptoms.

Recently H. H. Stone and his colleagues, ${ }^{8}$ dissatisfied with the results of treating patients with pulmonary burns (mortality $89 \%$ ), carried out experiments to evaluate present methods of therapy. They insufflated steam at $10 \mathrm{~mm}$. $\mathrm{Hg}$ pressure through a chilled, plastic, intratracheal tube for one to five second in rats. Their studies showed that treatment with $40 \%$ oxygen or $80-100 \%$ humidity reduced the mortality of the animals. Antibiotics failed to decrease mortality, and treatment with adrenal steroids appeared to be contraindicated.

Respiratory tract damage in burned patients is less common in Britain than in the United States. In Britain extensive burns affecting the face are usually the result of clothes being set alight from unguarded coal fires, and not from people being trapped in burning buildings. The victims, usually children, run about breathing normal air till the flames are put out. In this country only about $5 \%$ of patients admitted to hospital with domestic burns have received them in conflagrations, and a pulmonary lesion, because it is uncommon, tends to be missed until a disaster like the Dellwood Maternity Home fire, ${ }^{9}$ which killed 13 newborn babies, reminds us of the truism that "smoke is poison."

Clinically, the surgeon should suspect damage of the pulmonary tract from the circumstances in which the patient was burned. He must then assess the site of the damage. If the pharynx, larynx, and upper trachea alone are injured the patient will probably complain of a sore throat and hoarseness-possibly leading to stridor. He may also have a cough, with carbon particles in the sputum and perhaps flecks of blood. If pulmonary damage is present it may not be apparent for several hours, or it may kill the patient with anoxia in a matter of minutes.

Stone's classification of pulmonary damage into respiratory insufficiency, pulmonary oedema, and pulmonary infection is a practical one ; the first two stages may not be clinically obvious in a mild case.

Pulmonary insufficiency may last 24-36 hours. It is the result of narrowing of the smaller bronchi due to spasm, congestion, and oedema of the walls, and blocking with carbon particles, epithelium, fibrin, leucocytes, and mucus. This leads to laboured breathing with an expiratory wheeze. Anoxia is evident from restlessness and confusion, and it may lead to coma and permanent brain damage. Cyanosis is usual, but it may be masked by anaemia or the cherry-red of carbon monoxide poisoning. If rales are present within an hour the prognosis is grave, but even if they are absent the victim should be admitted to hospital overnight for observation like a case of concussion. A single normal chest radiograph is of no significance. Changing physical signs in the chest are probably due to transient atelectasis and filling of alveoli with exudate, epithelial debris, and white cells. Stone's work has shown the value of treating burned patients in this stage with $40 \%$ oxygen and $80-100 \%$ humidity. Positive-pressure ventilation did not appear to overcome hypoxia, and tracheostomy, except for associated laryngeal obstruction, may precipitate pulmonary oedema by reducing the intrapulmonary pressure produced by intermittent glottic obstruc-

1 Aub, J. C., Pittman, H., and Brues, A. M., Ann. Surg., 1943, 117, 834, Schatzki, R., ibid., 1943, 117, 841.

Schatzki, R., ibid., 1943, 117, 841. J., ibid., 1943, 117, 865.

- Mallory, T. B., and Brickley, W. J., ibid., 1943, 117, 865 . $1945,21,311$.

5 Phillips, A. W., and Cope, O., Ann. Surg., 1962, 155, 1.

- 1 ibid., 1962, 156, 759.

, Tanner, J. W., and Cope, O., ibid., 1963, 158, 799.

Stone, H. H., Rhame, D. W. Corbitt, J. D., Given, K. S., and Marün, J. D., ibid., 1967, 165, 157 .

- Cox, M. E., Heslop, B. F., Kempton, J. J., and Ratclif, R. A., Brit. med. F., 1955, 1, 942. 